\section{The Hidden Life of Trees - What they feel, how they communicate: Discoveries from a secret world}

Peter Wohlleben 2015. ISBN 978-1771642-484. Greystone Books/David Suzuki Institute, Vancouver/Berkley.

[This Review by Dr. Erin Zimmerman first appeared on the Canadian Science Publishing Blog 15/11 2017, and is republished here with permission from Dr. Zimmerman]

W alking through a quiet forest setting, the landscape can seem so peaceful and static that it's hard to even imagine the flurry of activity and strife going on beneath the soil and at scales smaller than we can see. At the centre of it all is the individual tree, struggling to get enough light, water, and nutrients to survive while vying against competing plant species, invasive insects, and furious winter storms.

The Hidden Life of Trees is a rambling journey through the various aspects of the life of a tree in the forest and focusses on the species common to Central European mixed deciduous-coniferous forests such as those found in Germany, where the book was originally published. In his conversational, easy-to-read style, author Peter Wohlleben discusses everything from mycorrhizal connections to how trees sense the passing of seasons. Each of the 36 short chapters covers a different topic. There is no overarching narrative, so each chapter feels like a standalone essay, which introduces a certain repetitiveness to some of them, but makes for easy bitesize consumption.

The author attempts to elucidate what is hidden to the naked eye: the complex interplay of different organisms that make up this ecosystem... trees, birds, mammals, fungi, insects, bacteria, and so forth. Wohlleben not only wants his readers to think about the lives of trees, but also to understand them in terms similar to our own.

A German forester-turned-conservationist who has been observing trees for over 20 years, Wohlleben has a great many anecdotes and observations to convey. Unfortunately, too often, the book relies on stating Wohlleben's opinions and observations as facts-mixed in with supported scientific knowledge, but not distinguished from it. The book's citations for scientific claims are sometimes problematic as well, citing corporate websites and seminars in place of peer-reviewed research.

Wohlleben at times displays a certain distain for those mainstream plant scientists espousing a strictly evidencebased view of trees and their abilities. He states that the majority of plant researchers get "worked up" about the idea of applying animal-based findings to plants, but that "the distinction between plant and animal is, after all, arbitrary." This is certainly not a view endorsed by conventional plant science, and Wohlleben doesn't present any compelling evidence to support it. The author even goes so far as to speculate that "the tree equivalent of a brain" is located in the roots, his only cited evidence being the opinion of a certain researcher at the University of Bonn and the presence of molecules similar to those found in animals.

The author doesn't necessarily seem to be aware of the state of research in certain fields he discusses, either. $\mathrm{He}$ contends that we know even less about life in the soil than we do about the ocean floor or the surface of the moon and that "researchers are only peripherally interested in the thousands of species discovered so far, having merely given them "unpronounceable Latin names." I suspect that the entire labs devoted to studying soilborne organisms, both ecologically and for agricultural purposes, would take issue with this assertion.

The other problematic aspect of this book comes from Wohlleben's constant need to anthropomorphize the trees he

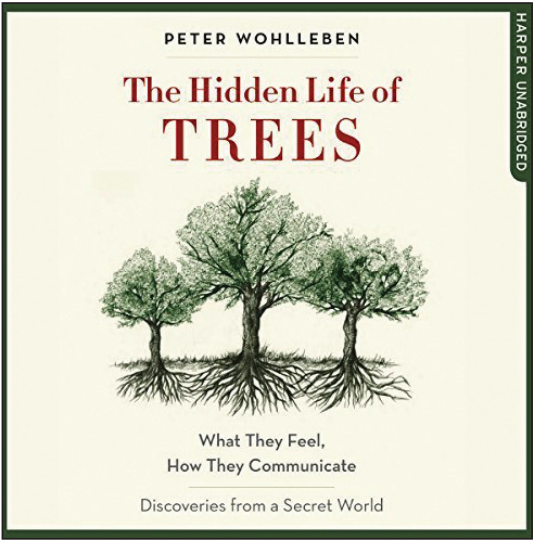

discusses. The early chapters of the book in particular are rife with trees being described as feeling affection toward one another, experiencing pain, possessing a sense of taste, and even having maternal instincts. Being colonized by symbiotic fungi, Wohlleben claims, "gives rise to positive feelings" within the tree. Some tree species are described as sociable and altruistic, while others are characterized as loners and bullies, imposing human values of positive and negative upon what are neutral traits evolved to aid in survival.

The author asks at one point why three trees growing under the same conditions should shed their leaves at different times, and he concludes that it is "a question of character" and the early shedder is simply "a bit more anxious." Whether this is Wohlleben's obscure way of explaining what likely amounts to individual genetic differences or whether he really thinks the individual trees have personalities is unclear, but this sort of fuzzy explanation doesn't serve to educate the lay reader on what is known about tree physiology. These sections of the book have the feel of Wohlleben wanting very much to believe that trees are simply a sort of immobile animal, with a rich inner life and complex society, even if scientific research has been unable to demonstrate the existence of these phenomena.

After some very speculative and problematic early chapters, however, Wohlleben settles into a more conventional style toward the middle of the 
book. These chapters, dealing with such topics as carbon dioxide levels, overwintering, and biodiversity within tree crowns ease off somewhat on discussing trees as animal-like creatures and instead successfully present some of the most compelling recent research into forest ecology and the physiology of trees. Here, Wohlleben shows that dramatic speculation and an anthropomorphic view aren't necessary to popularize the lives of trees.

We learn that ant colonies engage in a form of animal husbandry on the leaves of deciduous trees as they farm aphids for the sweet exudate the tiny insects produce at the expense of the tree. We learn that the roots of dead trees support the larvae of stag beetles, which may eat away at the crumbling wood for up to eight years before attaining their short-lived adult form. And we learn that when a deciduous tree sheds its leaves, in part to reduce wind resistance during winter storms, it is equivalent to "a sailboat with a 130-foot-tall mast dropping a 100-by-130-foot mainsail." It is in providing fascinating tidbits such as these that Wohlleben's warm tone and ability to deftly explain complex topics shine. At times, it feels like a glimpse into a different book.

The Hidden Life of Trees sets out to show readers how compelling the lives of trees and forests are, and how much activity lies beyond the naked eye. Wohlleben wants you to love trees as he does. The New York Times bestseller status of this book, as well as its runaway success in its original German, shows that he has been successful in this pursuit. And indeed, as a plant scientist, I too read a number of compelling facts that were new to me and that I will think back on whenever I next take a stroll in a forest.
I would point out the irony, however, of Wohlleben's need to frame these organisms as something close to humans or other animals. In attempting to make us love them, he feels he must present them as something different than what, according to scientific evidence, they really are. Yet trees are remarkable without human traits, as he shows when he moves to a more traditional approach for some parts of his book. With respect to the science presented, the lay reader would be well served by a disclaimer helping them to understand the book as one man's observations on and beliefs about forests, rather than a strictly scientific read."

Dr. Erin Zimmerman See: derinzimmerman.com 